\begin{tabular}{|c|c|}
\hline & $\begin{array}{l}\text { JAGROS Journal of Agrotechnonogy and Science } \\
\text { Jurnal Agroteknologi dan sains } \\
\text { Fakultas Pertanian, Universitas Garut } \\
\text { P ISSN : } 2775-0485, \text { E ISSN : } 2548-7752\end{array}$ \\
\hline
\end{tabular}

\title{
PENGARUH BERBAGAI PUPUK KANDANG DAN JARAK TANAM TERHADAP KEANEKARAGAMAN, DOMINANSI DAN LAJU TUMBUH GULMA PADA TANAMAN BAWANG MERAH (Allium ascalonicum $\mathbf{L}$.)
}

\author{
Anggi Septia Nugraha', Jenal Mutakin ${ }^{2}$, Novriza Sativa ${ }^{3}$ \\ Prodi Agroteknologi, Fakultas Pertanian, Univesitas Garut \\ Jalan Raya Samarang Nomor 52.A, Garut. \\ e-mail : anggiseptianugraha1 @ gmil.com
}

\begin{abstract}
Abstrak
Penelitian ini bertujuan untuk mengetahui interaksi antara berbagai pupuk kandang dan jarak tanam terhadap keanekaragaman, domonansi, laju tumbuh gulma dan untuk mengetahui pupuk dan jarak tanam manakah yang terbaik pada penekanan laju tumbuh gulma pada bawang merah. Penelitian dilaksanakan di Kp. Margahayu, Desa Caringin, Kecamatan Caringin, Kabupaten Garut. Penelitian ini menggunakan metode Rancangan Acak Kelompok (RAK) pola faktorial dengan 3 kali ulangan. Faktor pertama adalah jenis pupuk organik yaitu : $\mathrm{p}_{0}$ (tanpa pupuk organik $)=0$ ton/ha, $\mathrm{p}_{1}($ pupuk kandang sapi $)=20$ ton/ha, $\mathrm{p}_{2}($ pupuk kandang ayam $)=20$ ton/ha, dan $\mathrm{p}_{3}$ (pupuk kandang kambing) $=20$ ton/ha. Faktor kedua adalah jarak tanam yaitu $: \mathrm{j}_{1}$ $=15 \mathrm{~cm} \times 15 \mathrm{~cm}, \mathrm{j}_{2}=15 \mathrm{~cm} \times 20 \mathrm{~cm}$, dan $\mathrm{j}_{3}=20 \mathrm{~cm} \times 20 \mathrm{~cm}$. Hasil penelitian menunjukan terdapat keanekaraman gulma pada lahan pertanaman bawang merah, yaitu : Centella aciatica L., Metha x piperita L., Mimosa indica, Meniathes trifolrata L., Cyperus rotundus L., Amaratus viridis L., dan Colocasia esculenta. Gulma yang mendominasi di lahan pertanaman bawang merah terdapat pada golongan gulma daun lebar, yaitu : Centella aciatica L., sebesar 19,9089\%. Hasil analisis ragam menunjukan tidak terjadi interaksi antara pemberian berbagai pupuk kandang dan jarak tanam terhadap laju tumbuh gulma pada tanaman bawang merah. Secara mandiri penggunaan pupuk $\mathrm{p}_{2}$ (pupuk kandang ayam) $=20$ ton/ha setara dengan $7,2 \mathrm{~kg} / \mathrm{plot}$ memberikan pengaruh nyata terhadap bobot kering gulma dan laju pertumbuhan gulma.
\end{abstract}

Kata kunci: bawang merah, gulma, jarak tanam, dan pupuk organik.

\begin{abstract}
This research aims to examine the interaction between various manure and plant spacing on diversity, dominance, weed growth rate and to find out which fertilizers and spacing were best for suppressing weed growth rates on shallots. The research was conducted at Kp. Margahayu, Caringin Village, Caringin District, Garut Regency. This study used a factorial randomized block design (RBD) with 3 replications. The first factor is the type of organic fertilizer, namely: $p 0$ (without organic fertilizer) $=0$ tonnes $/$ ha, $p 1$ (cow manure) $=20$ tonnes $/$
\end{abstract}


ha, $p 2$ (chicken manure $)=20$ tonnes $/$ ha, and p3 (goat manure $)=20$ tons $/$ ha. The second factor is the spacing, namely: $j 1=15 \mathrm{~cm} \times 15 \mathrm{~cm}, j 2=15 \mathrm{~cm} \times 20 \mathrm{~cm}$, and $j 3=20$ $\mathrm{cm} \times 20 \mathrm{~cm}$. The results showed that there was a diversity of weeds in shallot fields, namely: Centella aciatica L., Metha x piperita L., Mimosa indica, Meniathes trifolrata L., Cyperus rotundus L., Amaratus viridis L., and Colocasia esculenta. Weeds that dominate in shallot fields are found in the broad leaf weeds, namely: Centella aciatica L., amounting to $19.9089 \%$. The results of the analysis of variance showed that there was no interaction between the application of various manure and spacing to the growth rate of weeds on shallot plants. Independent use of p2 fertilizer (chicken manure) $=20$ tonnes / ha equivalent to $7.2 \mathrm{~kg} /$ plot has a significant effect on weed dry weight and weed growth rate.

Keywords: shallots, weeds, spacing, and organic fertilizer

\section{Pendahuluan}

Bawang merah (Allium ascalonicum L.) merupakan salah satu komoditas tanaman hortikultura yang banyak dikonsumsi masyarakat sebagai campuran bumbu masak setelah cabe. Selain sebagai campuran bumbu masak, bawang merah juga dijual dalam bentuk olahan seperti ekstrak bawang merah, bubuk, minyak atsiri, bawang goreng bahkan sebagai bahan obat untuk menurunkan kadar kolesterol, gula darah, mencegah penggumpalan darah, menurunkan tekanan darah serta memperlancar aliran darah. Sebagai komoditas hortikultura yang banyak dikonsumsi masyarakat, potensi pengembangan bawang merah masih terbuka lebar tidak saja untuk kebutuhan dalam negeri tetapi juga luar negeri (Suriani, 2011).

Salah satu upaya untuk mendukung pertumbuhan bawang merah yang optimal adalah dengan pemupukan. Pemupukan bertujuan untuk menambah unsur hara yang dibutuhkan oleh tanaman sebab unsur hara yang terdapat di dalam tanah tidak selalu mencukupi untuk memacu pertumbuhan tanaman secara optimal (Salikin, 2003).

Pupuk organik mengandung unsur hara makro yang rendah tetapi juga mengandung unsur hara mikro dalam jumlah cukup yang sangat diperlukan dalam pertumbuhan tanaman karena mempengaruhi sifat fisik, sifat kimia, dan sifat biologi tanah. Mencegah erosi dan mengurangi keretakan tanah (Agromedia, 2007). Salah satu jenis pupuk organik yaitu pupuk kandang, pupuk kandang merupakan produk buangan dari binatang peliharaan seperti ayam, kambing, sapi yang dapat digunakan untuk menambah hara dalam tanah (Hanafiah, 2010).

Pemakaian pupuk kandang perlu dipertimbangkan, karena pupuk kandang dapat menyebabkan berkembangnya gulma pada lahan yang diusahakan, salah satu usaha yang dapat dilakukan untuk menekan hal tersebut adalah dengan penggunaan jenis pupuk kandang yang tepat. Adanya gulma pada pupuk kandang sangat dipengaruhi oleh proses penggembalaan lokasi ternak, karena setiap lingkungan akan membawa bibit gulma yang 
dimakan ternak berbeda-beda.Oleh karena lingkungan pengembalaan yang berbeda, maka gulma yang dimakan ternak juga berbeda (Zarwan et al., 1994).

Upaya yang dapat dilakukan untuk mengatasinya adalah dengan pengaturan jarak tanam. Pengaturan jarak tanam diperlukan agar tanaman dapat tumbuh optimal dan memberikan hasil yang baik tanpa mengalami persaingan baik antar tanaman maupun antara tanaman dan gulma (Basuki, 2009).

Keberadaan gulma disekitar pertanaman merupakan salah satu masalah penting dalam budidaya tanaman. Semakin beranekaragam gulma tumbuh bersama dengan tanaman pokok menyebabkan terjadinya persaingan, pertumbuhan tanaman pokok semakin terlambat, dan hasilnya semakin menurun (Pertiwi dan Arsyad, 2018).

Gulma yang sering ditemukan pada pertanaman bawang merah menurut Moenandir (2010), diantaranya Amaranthus spinosus, Portulaca oleracea, Cynodon dactylon, Cyperus rotundus, Imperata cylindrica, Echinochloa colona, Panicum repens, Eleusine indica.

Laju tumbuh gulma penting dipelajari untuk mengetahui komposisi dan struktur gulma pada lahan tanaman bawang merah serta menentukan pengendalian yang tepat. Banyak faktor yang mempengaruhi laju tumbuh gulma pada tiap lokasi pengamatan, seperti cahaya, unsur hara, pengolahan tanah, cara budidaya tanaman, jarak tanam atau kerapatan tanaman, serta umur tanaman bawang merah tersebut. Spesies gulma juga dipengaruhi oleh kerapatan tanaman, kesuburan tanah, pola budidaya dan pengolahan tanah (Aldrich et al., 1997).

Penelitian ini diharapkan dapat diketahui jenis pupuk kandang dan jarak tanam yang tepat, sehingga kerugian yang disebabkan oleh gulma dapat ditekan sekecil mungkin yang pada akhirnya akan diperoleh hasil bawang merah yang bagus. Berdasarkan beberapa penjelasan tersebut maka penulis tertarik untuk melakukan penelitian "Pengaruh Berbagai Pupuk Kandang dan Jarak Tanam Terhadap Keanekaragaman Dominansi dan Laju Tumbuh Gulma pada Tanaman Bawang Merah (Allium ascalonicum L.)".

\section{Metodologi}

\section{Tempat dan Waktu}

Penelitian dilaksanakan di Kp. Margahayu, Desa Caringin, Kecamatan Caringin, Kabupaten Garut dengan ketinggian tempat $738 \mathrm{~m}$ di atas permukaan laut yang telah dilaksanakan pada bulan September sampai Oktober 2020.

\section{Objek, Bahan dan Alat Penelitian}

Objek yang digunakan dalam penelitian ini adalah gulma yang tumbuh di pertanaman bawang merah. Bahan yang digunakan dalam penelitian ini adalah bibit bawang merah, pupuk kandang ayam, kambing dan sapi. Sedangkan alat yang digunakan adalah gunting, wadah, kantong plastik, kantong kertas, timbangan analitik, alat tulis, penggaris dan kuadran. 
Dalam penelitian ini digunakan Rancangan Acak Kelompok (RAK) faktorial yang terdiri dari dua faktor. Faktor pertama adalah jenis pupuk organik dengan 4 taraf : p0 $($ tanpa pupuk organik) $=0$ ton/ha, $\mathrm{p} 1$ (pupuk kandang sapi) $=20$ ton/ha setara dengan 7,2 $\mathrm{kg} / \mathrm{plot}, \mathrm{p} 2$ (pupuk kandang ayam) $=20$ ton/ha setara dengan 7,2 kg/plot, p3 (pupuk kandang kambing $)=20$ ton $/$ ha setara dengan $7,2 \mathrm{~kg} / \mathrm{plot}$. Faktor kedua adalah jarak tanam yang terdiri atas : $\mathrm{j} 1=15 \mathrm{~cm} \times 15 \mathrm{~cm}, \mathrm{j} 2=15 \mathrm{~cm} \times 20 \mathrm{~cm}, \mathrm{j} 3=20 \mathrm{~cm} \times 20 \mathrm{~cm}$.

\section{Hasil dan Pembahasan}

\section{Identifikasi Gulma}

Hasil pengamatan gulma pada lahan pertanaman bawang merah dengan pemberian beberapa pupuk kandang dan sistem jarak tanam yang berbeda menunjukan bahwa jenis gulma yang ada di lahan penelitian terdapat 2 golongan gulma terdiri atas 7 jenis gulma. Data hasil identifikasi dapat dilihat pada Tabel 3.

Tabel 1. Identifikasi Gulma pada Lahan Tanaman Bawang Merah

\begin{tabular}{clll}
\hline No & \multicolumn{1}{c}{ Nama Jenis } & \multicolumn{1}{c}{ Famili } & \multicolumn{1}{c}{ Nama Lokal } \\
\hline 1 & Teki & & Teki Ladang \\
& $\begin{array}{l}\text { Cyperus rotundus } \text { L. } \\
\text { Daun Lebar }\end{array}$ & Cyperaceae & \\
& Centella aciatica L. & Apiaceae & Antanan \\
& Mentha x piperita L. & Lamiaceae & Daun mint \\
& Amaratus viridis L. & Amaranthaceae & Bayam Hijau \\
& Mimosa indica & Fabaceae & Putri Malu \\
& Menyanthes trifoliata L. & Menyanthaceae & \\
& Colocasia esculenta & Araceae & Talas \\
\hline
\end{tabular}

Sumber: Hasil Pengamatan Anggi, 2021

Data pada Tabel 3. menunjukkan bahwa spesies gulma yang termasuk ke dalam gulma teki terdapat 1 spesies, yaitu : Cyperus rotundus L. Serta terdapat 6 spesies gulma berdaun lebar, yaitu : Centella aciatica L., Mentha x piperita L., Amaratus viridis L., Mimosa indica, Menyanthes trifoliata L., dan Colocasia esculenta. Kegiatan identifikasi ini dilakukan berdasarkaan Hand Book on Weed Identification Directorate of Weed Science Research yang ditulis oleh Naidu, V.S.G.R.

Jumlah jenis gulma paling banyak ditemukan yaitu gulma berdaun lebar sebanyak 5 jenis. Hal ini diduga karena gulma berdaun lebar dapat hidup di lingkungan yang tanahnya subur serta tersinari matahari. Sejalan dengan pernyataan Subrata dan Setiawan (2018) bahwa gulma berdaun lebar memiliki daya adaptasi yang tinggi dan merupakan salah satu jenis gulma yang mengganggu pertumbuhan dan hasil tanaman budidaya.

Pada saat penelitian berlangsung pada musim hujan sehingga pertumbuhan gulma cepat karena kebutuhan air tercukupi untuk tanaman utama dan gulma. Menurut Moenandir (2010); Lubis (1992) yang mempengaruhi jumlah spesies yang hidup pada 
suatu komunitas yaitu cahaya, dimana cahaya sangat berpengaruh terhadap jenis dan jumlah individu yang dapat tumbuh di tempat tersebut.

\section{Indeks Keanekaragaman Spesies (H')}

Hasil analisis gulma pada lahan pertanaman bawang merah dengan pemberian beberapa pupuk kandang dan sistem jarak tanam yang berbeda menunjukan hasil indeks keragaman gulma yang rendah karena rata-rata jumlah indeks keragaman gulma tiap rendah $\left(\mathrm{H}^{\prime}<1\right)$. Indek keanekaragaman spesies yang tinggi menunjukkan bahwa suatu komunitas memiliki kompleksitas tinggi karena interaksi spesies yang tinggi dalam komunitasnya dan jika komunitas itu disusun oleh banyak spesies dan sebaliknya, suatu komunitas dikatakan memiliki keanekaragaman spesies yang rendah jika komunitas itu disusun oleh sedikit spesies dan jika hanya ada sedikit saja spesies yang dominan (Indriyanto, 2010).

Keanekaragaman Spesies ( $\left.\mathrm{H}^{\prime}\right)$ pada suatu komoditas dengan menggunakan rumus menurut Barbour, Burk dan Pitts (1987) dapat di tafsirkan maknanya maka digunakan criteria menurut Magurran, (1988: 35): $\mathrm{H}^{\prime}<1=$ Keanekaragaman rendah, $\mathrm{H}^{\prime}<3=$ Keanekaragaman sedang dan H'>3 = Keanekaragaman tinggi.

Data pada tabel 4 menunjukan bahwa terdapat 7 spesies gulma pada lahan pertanaman bawang merah yang menyebabkan terjadinya persaingan untuk mendapatkan unsur hara dalam tanah. Spesies gulma golongan daun lebar yang memiliki indeks keanekaragaman tertinggi, yaitu : Centella aciatica L. sebesar 0,34263 dan spesies gulma yang mememiliki indeks keanekaragaman gulma rendah yaitu : Colocasia esculenta sebesar 0,035. Menurut Dalimartha (2006) Centella aciatica L. mudah tumbuh dan mempunyai daya adaptasi yang luas. Centella aciatica L. tumbuh baik pada tanah yang agak lembap, tetapi cukup sinar matahari atau agak terlindung. Centella aciatica L. tumbuh optimun di dataran medium pada ketinggian sekitar $700 \mathrm{~m} \mathrm{dpl,} \mathrm{namun} \mathrm{juga}$ mampu tumbuh di daerah tinggi hingga 2.500 m dpl (Heyne 1987; Dalimartha 2000).

Tabel 2. Indeks Keanekaragaman Gulma pada Lahan Tanaman Bawang Merah

\begin{tabular}{clc}
\hline No & \multicolumn{1}{c}{ Gulma } & Indeks Keanekaragaman $\left(H^{\prime}\right)$ \\
\hline 1 & Centella aciatica $\mathrm{L}$. & 0,34263 \\
2 & Metha x piperita $\mathrm{L}$. & 0,31372 \\
3 & Mimosa indica & 0,33263 \\
4 & Meniathes trifolrata $\mathrm{L}$. & 0,28938 \\
5 & Cyperus rotundus $\mathrm{L}$. & 0,27655 \\
6 & Amaratus viridis $\mathrm{L}$. & 0,14873 \\
7 & Colocasia esculenta & 0,035 \\
\hline & $\mathrm{N}$ & 1,73864 \\
\hline
\end{tabular}




\section{Summed Dominance Ratio (SDR)}

Nilai SDR digunakan untuk menggambarkan jumlah dominansi suatu jenis gulma dengan jenis gulma lain dalam satu komunitas. Dominansi merupakan kemampuan suatu jenis gulma untuk dapat bersaing dengan jenis gulma lainnya dan bertahan hidup dalam suatu agroekosistem tertentu. Kondisi ini ditunjukkan dengan beberapa gulma yang lebih banyak jumlahnya dibandingkan dengan beberapa gulma lainnya (Tjitrosoedirdjo et al., 1984). Hasil data analisis SDR gulma pada lahan pertanaman bawang merah dengan pemberian beberapa pupuk kandang dan sistem jarak tanam yang berbeda dapat dilihat pada Tabel 5 .

Hasil anaslisi pada Tabel 5. menunjukan gulma yang memiliki nilai SDR tertinggi pada lahan pertanaman bawang merah terdapat pada golongan gulma daun lebar, yaitu : Centella aciatica L. sebesar 19,9089\%. Hal ini diduga karena penyebaran gulma Centella aciatica L. cukup luas dan banyak dijumpai pada lahan pertanian yang dapat merugikan tanaman bawang merah karena perebutan unsur hara dan mineral yang dibutuhkan tanaman untuk tumbuh. Menurut Januwati dan Muhammad (1992), Centella aciatica L merupakan tumbuhan tropis dengan daerah penyebaran cukup luas, dari dataran rendah sampai dataran tinggi, hingga $2.500 \mathrm{~m}$ di atas permukaan laut.

Tabel 3. Nilai SDR ( Summed Dominance Ratio ) Gulma pada Lahan Tanaman Bawang Merah

\begin{tabular}{|c|c|c|}
\hline No & Gulma & Summed Dominance Ratio (SDR) (\%) \\
\hline 1 & Centella aciatica $\mathrm{L}$. & 19,9089 \\
\hline 2 & Metha $x$ piperita $\mathrm{L}$. & 17,2587 \\
\hline 3 & Mimosa indica & 18,8488 \\
\hline 4 & Meniathes trifolrata $\mathrm{L}$. & 15,6686 \\
\hline 5 & Cyperus rotundus $\mathrm{L}$. & 14,9619 \\
\hline 6 & Amaratus viridis $\mathrm{L}$. & 10,3682 \\
\hline 7 & Colocasia esculenta & 2,98494 \\
\hline
\end{tabular}

Keterangan: Angka rata-rata yang diikuti huruf yang sama pada setiap kolom, tidak berbeda nyata menurut Uji Jarak Berganda Duncan pada taraf nyata 5\%.

Gulma daun lebar jenis Colocasia esculenta dengan nilai SDR 2,98494\% dengan nilai SDR paling rendah dibanding gulma lainnya. Perbedaan pertumbuan gulma pada suatu lahan tergantung pada jenis tanaman budidaya, jenis tanah, iklim dan pola tanam. Dimana derajat persaingan antara gulma dan tanaman tergantung pada densitas jenis gulma, varietas tanaman dan tingkat pemupukan (Hasanuddin et al., 2012).

Sebagian besar gulma yang memperbanyak diri dengan biji adalah gulma semusim, biji yang diproduksi dalam satu musim dapat digunakan untuk generasi berikutnya karena sebagian dari biji tersebut tersimpan di dalam tanah. Apabila tanah diolah maka biji tersebut akan muncul ke permukaan tanah dan berkecambah. Sehingga gulma-gulma 
tersebut akan mengalami penambahan jumlah di suatu areal pertanaman (Mangoensoekarjo dan Soejono, 2015).

\section{Bobot Kering Gulma}

Hasil analisis ragam menunjukan tidak terjadi interaksi antara pemberian beberapa pupuk kandang dan sistem jarak tanam terhadap bobot kering gulma pada lahan pertanaman bawang merah, tetapi secara mandiri pemberian beberapa pupuk kandang menunjukkan pengaruh nyata terhadap bobot kering gulma pada umur 30 setelah olah tanah (SOT). Hasil analisis data rata-rata bobot kering gulma dapat dilihat pada Tabel 6.

Tabel 4. Bobot Kering Gulma pada Lahan Tanaman Bawang Merah

\begin{tabular}{|c|c|c|c|}
\hline \multirow{2}{*}{ Perlakuan } & \multicolumn{3}{|c|}{ Bobot Kering Gulma (g) } \\
\hline & $10 \mathrm{SOT}$ & $20 \mathrm{SOT}$ & $30 \mathrm{SOT}$ \\
\hline \multicolumn{4}{|l|}{ Jenis Pupuk Organik } \\
\hline $\mathrm{p}_{0}$ (tanpa pupuk organik) & $0,10 \mathrm{a}$ & $0,10 \mathrm{a}$ & $0,66 \mathrm{a}$ \\
\hline $\mathrm{p}_{1}$ (pupuk kandang sapi) & $0,04 \mathrm{a}$ & $0,21 \mathrm{a}$ & $0,95 \mathrm{a}$ \\
\hline $\mathrm{p}_{2}$ (pupuk kandang ayam) & $0,10 \mathrm{a}$ & $0,08 \mathrm{a}$ & $1,67 \mathrm{~b}$ \\
\hline $\mathrm{p}_{3}$ (pupuk kandang kambing) & $0,01 \mathrm{a}$ & $0,13 \mathrm{a}$ & $1,17 \mathrm{a}$ \\
\hline \multicolumn{4}{|l|}{ Jarak Tanam } \\
\hline $\mathrm{j}_{1}(15 \mathrm{~cm} \times 15 \mathrm{~cm})$ & $0,14 \mathrm{a}$ & $0,14 \mathrm{a}$ & $1,85 \mathrm{a}$ \\
\hline $\mathrm{j}_{2}(15 \mathrm{~cm} \times 20 \mathrm{~cm})$ & $0,13 \mathrm{a}$ & $0,39 \mathrm{a}$ & $1,88 \mathrm{a}$ \\
\hline $\mathrm{j}_{3}(20 \mathrm{~cm} \times 20 \mathrm{~cm})$ & $0,05 \mathrm{a}$ & $0,16 \mathrm{a}$ & $2,21 \mathrm{a}$ \\
\hline
\end{tabular}

Keterangan: Angka rata-rata yang diikuti huruf yang sama pada setiap kolom, tidak berbeda nyata menurut Uji Jarak Berganda Duncan pada taraf nyata $5 \%$.

Hasil analisis pada Tabel 6. menunjukan bahwa pemberian berbagai jenis pupuk umur 30 SOT pada taraf $\mathrm{p}_{2}$ berbeda nyata dengan $\mathrm{p}_{0}, \mathrm{p}_{1}$ dan $\mathrm{p}_{3}$, sedangkan $\mathrm{p}_{0}$ tidak berbeda nyata dengan $\mathrm{p}_{1}$ dan $\mathrm{p}_{3}$. Hal ini diduga karena pemberian pupuk selain diserap oleh tanaman bawang merah juga diserap oleh gulma untuk proses fotosintesis yang menyebabkan meningkatnya bobot kering gulma. Pertumbuhan bawang merah juga secara visual bagus dengan pemberian pupuk kandang ayam dibanding tanpa pemberian pupuk.

Sejalan dengan pernyataan Pujisiswanto et al., (2015) bobot kering gulma mencerminkan pola gulma mengakumulasikan produk dari proses fotosintesis dan merupakan integrasi dengan faktor-faktor lingkungan lainnya seperti jenis tanah, iklim, tingkat pemupukan dan pola tanam.

Semakin berat bobot kering suatu gulma, pertumbuhannya semakin baik, dan tentunya penguasaan lahan dan daya saingnya terhadap tanaman juga semakin tinggi. Bobot kering gulma total semakin meningkat dengan bertambahnya umur gulma merupakan indikator pertumbuhan hasil penimbunan bahan kering gulma yang dihasilkan pada proses fotosintesis tanpa adanya penghambatan pertumbuhan. 


\section{Laju Tumbuh Gulma}

Hasil analisis ragam menunjukan tidak terjadi interaksi antara pemberian beberapa pupuk kandang dan sistem jarak tanam terhadap laju tumbuh gulma pada lahan pertanaman bawang merah, tetapi secara mandiri pemberian beberapa pupuk kandang menunjukkan pengaruh nyata terhadap laju tumbuh gulma pada umur 30 SOT. Hasil analisis data ratarata laju tumbuh gulma dapat dilihat pada Tabel 7.

Hasil analisis menunjukan bahwa pemberian berbagai jenis pupuk umur 30 SOT pada taraf $\mathrm{p}_{2}$ berbeda nyata dengan $\mathrm{p}_{0}, \mathrm{p}_{1}$ dan $\mathrm{p}_{3}$, sedangkan $\mathrm{p}_{0}$ tidak berbeda nyata dengan $\mathrm{p}_{1}$ dan $\mathrm{p}_{3}$. Hal ini diduga karena gulma dapat dengan mudah tumbuh, memiliki daya tahan yang tinggi, pertumbuhan gulma sangat cepat meningkat dan mudah beradaptasi dengan lingkungan tumbuh sehingga mempengaruhi laju pertumbuhannya.

Menurut Moenandir (1993) bahwa gulma dapat tumbuh pada setiap tempat yang berbeda-beda mulai dari tempat yang miskin nutrisi sampai yang kaya nutrisi. Didukung juga oleh pendapat Rukmana dan Saputra (1999) bahwa sifat sifat umum yang dimiliki gulma adalah cepat berkembang biak, periode pembungaan cukup lama, pembentukan biji berlainan umur, bunga umumnya majemuk, berbiji banyak, sifat dominasi biji yang lama, daya adaptasi yang luas dan tahan terhadap lingkungan yang kurang menguntungkan.

Tabel 5. Laju Tumbuh Gulma pada Lahan Tanaman Bawang Merah

\begin{tabular}{|l|c|c|c|}
\hline \multirow{2}{*}{\multicolumn{1}{|c|}{ Perlakuan }} & \multicolumn{2}{c|}{ Laju Tumbuh Gulma $\left(\mathrm{g} / \mathrm{m}^{2} / \mathrm{minggu}\right)$} \\
\cline { 2 - 4 } & 10 SOT & 20 SOT & 30 SOT \\
\hline Jenis Pupuk Organik & & & \\
\hline $\mathrm{p}_{0}$ (tanpa pupuk organik) & $0,00008 \mathrm{a}$ & $0,00008 \mathrm{a}$ & $0,00051 \mathrm{a}$ \\
\hline $\mathrm{p}_{1}$ (pupuk kandang sapi) & $0,00003 \mathrm{a}$ & $0,00016 \mathrm{a}$ & $0,00074 \mathrm{a}$ \\
\hline $\mathrm{p}_{2}$ (pupuk kandang ayam) & $0,00007 \mathrm{a}$ & $0,00006 \mathrm{a}$ & $0,00129 \mathrm{~b}$ \\
\hline $\mathrm{p}_{3}$ (pupuk kandang kambing) & $0,00001 \mathrm{a}$ & $0,00010 \mathrm{a}$ & $0,00090 \mathrm{a}$ \\
\hline Jarak Tanam & & & \\
\hline $\mathrm{j}_{1}(15 \mathrm{~cm} \times 15 \mathrm{~cm})$ & $0,00011 \mathrm{a}$ & $0,00011 \mathrm{a}$ & $0,00143 \mathrm{a}$ \\
\hline $\mathrm{j}_{2}(15 \mathrm{~cm} \times 20 \mathrm{~cm})$ & $0,00010 \mathrm{a}$ & $0,00030 \mathrm{a}$ & $0,00145 \mathrm{a}$ \\
\hline $\mathrm{j}_{3}(20 \mathrm{~cm} \times 20 \mathrm{~cm})$ & $0,00004 \mathrm{a}$ & $0,00013 \mathrm{a}$ & $0,00170 \mathrm{a}$ \\
\hline
\end{tabular}

Keterangan: Angka rata-rata yang diikuti huruf yang sama pada setiap kolom, tidak berbeda nyata menurut Uji Jarak Berganda Duncan pada taraf nyata 5\%.

\section{Kesimpulan}

Berdasarkan hasil penelitian mengenai pengaruh berbagai pupuk kandang dan jarak tanam terhadap laju tumbuh gulma pada tanaman bawang merah (Allium ascalonicum L.) dapat disimpulkan sebagai berikut. 
1. Keanekaraman menunjukan bahwa terdapat 7 spesies gulma pada lahan pertanaman bawang merah, yaitu : Centella aciatica L., Metha $x$ piperita L., Mimosa indica, Meniathes trifolrata L., Cyperus rotundus L., Amaratus viridis L., dan Colocasia esculenta.

2. Gulma yang mendominasi yang memiliki nilai SDR tertinggi pada lahan pertanaman bawang merah terdapat pada golongan gulma daun lebar, yaitu : Centella aciatica L., sebesar 19,9089\%.

3. Tidak terjadi interaksi antara penggunaan berbagai pupuk kandang dan jarak tanam terhadap laju tumbuh gulma pada tanaman bawang merah.

4. Secara mandiri penggunaan pupuk p2 (pupuk kandang ayam) $=20$ ton/ha setara dengan $7,2 \mathrm{~kg} /$ plot memberikan pengaruh nyata terhadap bobot kering gulma dan laju pertumbuhan gulma.

\section{Daftar Pustaka}

Agromedia. 2007. Petunjuk Pemupukan. Jakarta : Agromedia Pustaka.

Aldrich, R.J. and R.J. Kremer. 1997. Principles in Weed Management. Second Edition. Iowa State University Press, Ames Iowa.

Basuki RS. 2009. Analisis kelayakan teknis dan ekonomis teknologi budidaya bawang merah dengan benih biji botani dan benih umbi tradisional. J Hort 19 (2): 214-227.

Dalimartha, S. 2000. Atlas Tumbuhan Obat Indonesia Jilid 2. Trubus Agriwidya, Jakarta.

Hanafiah, K. A. 2010. Dasar-dasar Ilmu Tanah. PT. Raja Grafindo Persada. Jakarta. 390.

Hasanuddin, Erida, G. dan Safmaneli. 2012. Pengaruh Persaingan Gulma Synedrella nodiflora L. pada Berbagai Densitas Terhadap Pertumbuhan Hasil Kedelai. Jurnal Agrista. Vol. 16(3): 146-152.

Heyne, K. 1987. Tumbuhan Berguna Indonesia Jilid 1ll. Terjemahan Badan Litbang Kehutanan. Yayasan Sarana Wana Jaya, Jakarta.

Januwati M dan Muhammad H. 1992. Cara Budidaya Pegagan (Centella asiatica L.). Warta tumbuhan Obat Indonesia 1(2): 42-44.

Lubis, A., 1992. Kelapa Sawit (Elaeis quineensis Jacq). Pusat Penelitian Perkebunan. Bandar Kuala Pematang Siantar Sumatera Utara.

Mangoensoekarjo, S. dan Soejono, A.T. 2015. Ilmu Gulma dan Pengelolaan Pada Budi Daya Perkebunan. Gadjah Mada University Press anggota IKAPI. Yogyakarta.

Moenandir, J., 2010. Pengantar Ilmu dan Pengendalian Gulma. Universitas Brawijaya Press. Malang.

Pertiwi, E.,D., dan Arsyad, M. 2018. Keanekaragaman dan Dominansi Gulma pada Pertanaman Jagung di Lahan Kering Kecamatan Marisa Kabupaten Pohuwato. Jurnal Perbal. Vol. 6 No. 3, Hlm. 31-39.

Pujisiswanto, H., Yudono, P., Sulistyaningsih, E., dan Sunarminto, B.H. 2015. Analisis Pertumbuhan Gulma Pada Aplikasi Asam Asetat Sebagai Herbisida Pascatumbuh. Universitas Lampung Press. Lampung. 
Rukmana R., dan S. Saputra. 1999. Gulma dan Teknik Pengendaliannya. Kanisius. Yogyakarta.

Salikin. 2003. Sistem Pertanian Berkelanjutan. Kanisius. Yogyakarta.

Subrata, B.A.G., dan Setiawan, B.A. 2018. Keragaman Vegetasi Gulma di Bawah Tegakan Pohon Karet (Hevea brasiliensis) pada Umur dan Arah Lereng yang Berbeda di PTPN IX Banyumas. Jurnal Ilmiah Pertanian. Vol. 14 No.2.

Suriani, N. 2011. Bawang Bawa Untung Budidaya Bawang Merah dan Bawang Putih. Cahaya Atma Pustaka. Yogyakarta.

Zarwan, Syahril, \& Mulyono. 1994. Studi pertumbuhangulma pada beberapa jenis pupuk kandang.Prosiding Konferensi XII Himpunan Ilmu Gulma Indonesia. Padang Sumatera Utara. 5 hal.160). 